\title{
Facts about Potassium ${ }^{1}$
}

\author{
R. Elaine Turner and Linda B. Bobroff ${ }^{2}$
}

\section{Why do we need potassium?}

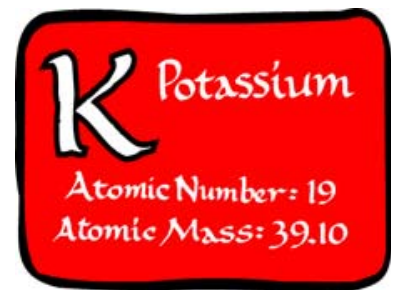

Potassium is a mineral found inside body cells. It is one of several minerals known as electrolytes. These minerals (potassium, sodium, and chloride) are found in the fluids inside and outside of body cells.

Potassium is important because it helps:

- regulate fluid and electrolyte balance

- maintain normal blood pressure

- transmit nerve impulses

- control muscle contraction, including the heart

- maintain healthy bones

\section{What happens if we don't get enough potassium?}

Potassium deficiency is rare. People with kidney problems, excessive diarrhea or vomiting, and those who use laxatives could have low potassium levels. Symptoms of low potassium in the body include weakness, poor appetite, nausea, and fatigue. Low potassium intake has been linked to hypertension and osteoporosis.

\section{How much potassium do we need?}

The following table lists recommended daily intakes of potassium.

\begin{tabular}{|l|c|}
\hline \multicolumn{1}{|c|}{ Life Stage } & $\begin{array}{c}\text { Potassium } \\
\text { (mg/day)* }\end{array}$ \\
\hline Men, ages 19+ & 4700 \\
\hline Women, ages, 19+ & 4700 \\
\hline Pregnancy & 4700 \\
\hline Breastfeeding & 5100 \\
\hline *mg = milligrams \\
\hline
\end{tabular}

\section{What does potassium have to do with high blood pressure?}

Studies show that eating the recommended level of potassium can help maintain normal blood pressure. The best results occur when sodium intake is kept low.

Eating enough potassium can

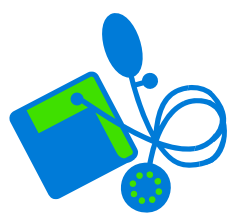
also reduce risk for stroke, and may reduce bone loss. A potassium-rich diet can also reduce the risk for kidney stones.

1. This document is FCS8805, one of a series of the Department of Family, Youth, and Community Sciences, Florida Cooperative Extension Service, Institute of Food and Agricultural Sciences, University of Florida. Publication date: November 2006. Please visit the EDIS Web site at http://edis.ifas.ufl.edu.

2. R. Elaine Turner, PhD, RD, associate dean, and Linda B. Bobroff, professor, Department of Family, Youth, and Community Sciences, Cooperative Extension Service, Institute of Food and Agricultural Sciences, University of Florida, Gainesville, FL 32611. 


\section{How can we get enough potassium?}

Potassium is readily available in our food supply, especially in unprocessed foods. Fruits and vegetables are the best sources. Dry beans and peas, nuts, and seeds are also good sources of potassium.

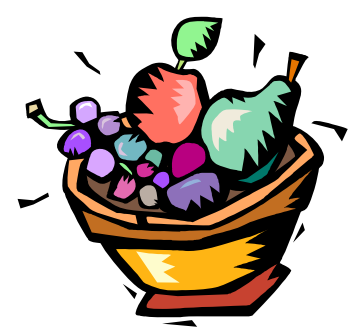

Here are some foods and the amount of potassium they contain.

\begin{tabular}{||l|c||}
\hline \multicolumn{1}{|c|}{ Food } & $\begin{array}{c}\text { Potassium } \\
\text { (mg/serving) }\end{array}$ \\
\hline $\begin{array}{l}\text { Potato, baked with skin, } \\
1 \text { medium }\end{array}$ & 930 \\
\hline Spinach, cooked, 1 cup & 840 \\
\hline Pinto beans, cooked, 1 cup & 750 \\
\hline Lentils, cooked, 1 cup & 730 \\
\hline Plantain, cooked, 1 cup & 720 \\
\hline Prunes, dried, 10 & 615 \\
\hline Banana, 1 large & 490 \\
\hline Orange juice, 1 cup & 470 \\
\hline Cantaloupe, pieces, 1 cup & 430 \\
\hline Papaya, pieces, 1 cup & 360 \\
\hline *mg = milligram & \\
\hline
\end{tabular}

\section{What about supplements?}

Because potassium is widely available in foods, supplements aren't usually needed. Some people who take diuretic medication for blood pressure control may need to get more potassium but this isn't true for all types of diuretics. Check with your doctor before taking a potassium supplement or using a salt substitute that contains potassium chloride.

\section{How much is too much?}

People who take diuretic medications or who have kidney disease should check with their doctor about proper potassium intake. Consuming more than five times the suggested amount of potassium can lead to hyperkalemia - high levels of potassium in the blood. Hyperkalemia can cause a heart attack and be fatal.

\section{Where can I get more information?}

The Family and Consumer Sciences (FCS) agent at your county Extension office may have more written information and nutrition classes for you to attend. Also, a registered dietitian (RD) can provide reliable information to you.

Reliable nutrition information may be found on the Internet at the following sites:

http://solutionsforyourlife.ufl.edu http://www.nutrition.gov http://www.nhlbi.nih.gov http://americanheart.org 